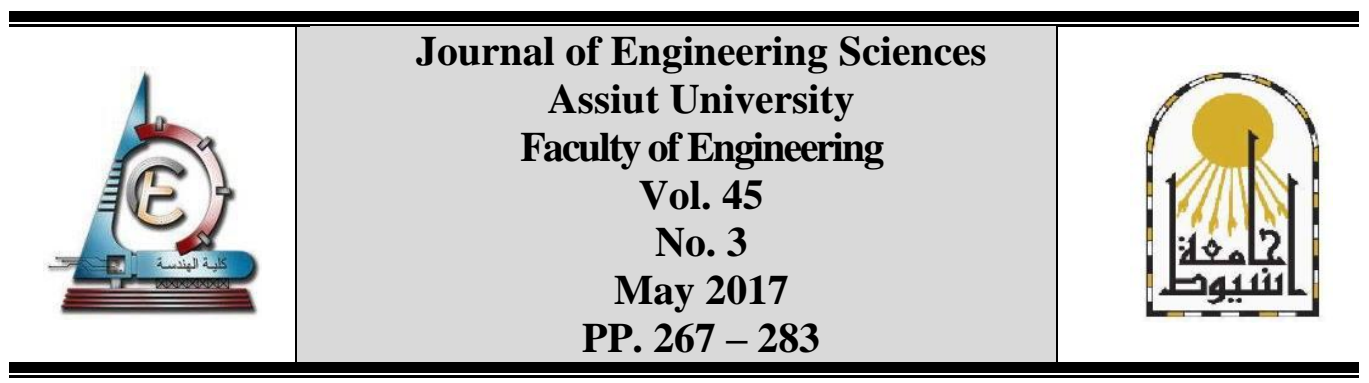

\title{
EFFECT OF UNDERGROUND FLOOR(S) ON SEISMIC ANALYSIS OF BUILDINGS
}

\author{
Magdy. M. M. Genidi ${ }^{1,}$ * Tamer M. S. Elsaied $^{2}$ \\ ${ }^{1}$ Department of Structural Engineering, Faculty of Engineering, Helwan University \\ ${ }^{2}$ Design Engineer, Mamdouh Hamza Office for Engineering Consultancy, Cairo, Egypt.
}

Received 5 January 2017; Accepted 9 March 2017

\begin{abstract}
This study investigates the effect of underground floor(s) on seismic analysis of buildings. Because the underground floor(s) is more rigid relative to the super structure, some codes have stated that in the seismic analysis of such buildings the base is defined as the top of underground floor(s). A parametric study was established using the response spectrum analysis method. Finite element simulations are conducted using ANSYS program to investigate the effect of underground floor(s). Results are presented for different buildings by varying the number of floors for the super structure $(2,5,10,15$ and 20), the number of underground floor (1 and 3) and spring support stiffness.
\end{abstract}

The numerical results of the considered cases show that the seismic loads applied to a building considering underground floor(s) affect the lateral force distribution and member forces of the building. Thus, it is obligatory to include the underground floor(s) in the seismic analysis of the considered buildings.

\section{Introduction}

Many buildings have underground floor(s) which are used as parking for lots or shopping malls etc. The current state of practice for seismic analysis of buildings with underground floor(s) involves approximate approaches that primarily differ according to the designer's judgment and experience. This is a consequence of lack of relevant recommendations in building codes. Because of the high rigidity of the underground floor(s)(due to the presence of rigid floor(s) diaphragms and R.C. perimeter walls) relative to the superstructure, some codes such as the Euro Code[1] have stated that in the seismic analysis of such buildings, the base is defined as the top of underground floor(s). Following this definition, some designers crop the superstructure and analyze it as a fixed base structure founded on the ground surface. The reactions resulting from such approach are then reversed on the underground floor(s) and are analyzed separately. However, if the underground floor(s) is considered in the analysis, the natural period of the structure is

* Corresponding author.

Email address: magdy_genidi@yahoo.com 
increased which results in the decrease of the base shear thus affecting the lateral displacements and the internal straining actions $[3,4,5]$.

The main objective of this study to better understands the seismic performance of buildings with underground floor(s). Therefore, in this study the natural period, the lateral displacement and the internal straining actions are carefully investigated for buildings the analysis of such buildings considers the underground floor(s) presence and are then compared with those of buildings where the underground floor(s) are not considered in the analysis. To achieve this objective, response spectrum analysis is conducted for 3D intermediate moment frame building with a superstructure ranging from two to twenty stories and underground floor(s) ranging from zero (i.e. no basement) to three basement. The foundation is either a fixed base foundation or a raft with Winkler type foundation support.

\section{Problem description}

\subsection{Example building (1) (Square building)}

A typical flat slab with $3 \times 3$ bay spans supported by moment resisting frame system having a constant bay span width of $7.00 \mathrm{~m}$ and story height of $3.00 \mathrm{~m}$ is used as an example building to investigate the effect of underground floor(s). Figure 1 shows the plan of repetitive story slab. The thickness of the slab is taken as $0.30 \mathrm{~m}$ to fulfill the safety requirements against slab design (deflection, punch, etc.). The thickness of underground floor(s) walls is taken as $0.30 \mathrm{~m}$ to fulfill the safety requirements against earth pressure. Columns cross sections are taken according to the design requirements of gravity loads with margin factor of safety for the additional straining actions from seismic analysis. The column cross-section was reduced every five stories as shown in Table 1.

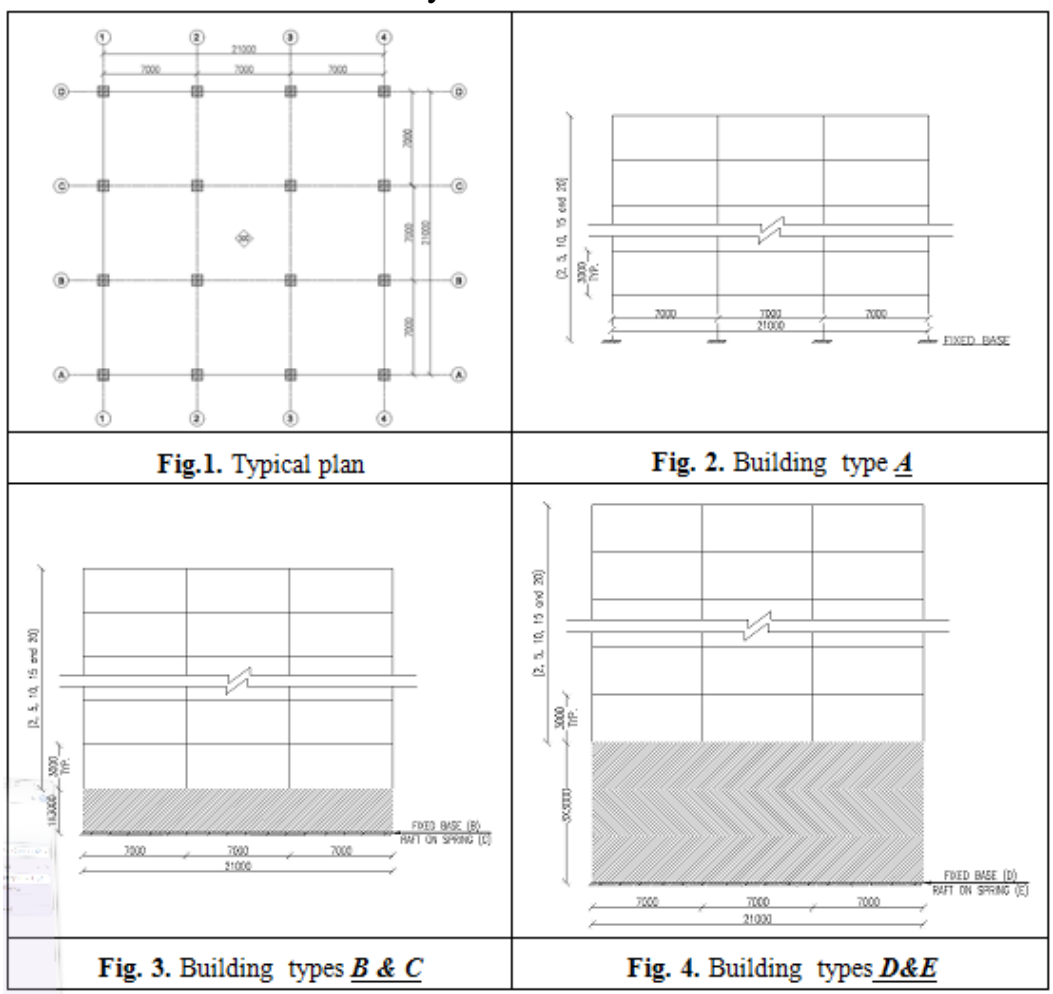


Magdy. M. M. Genidi and Tamer M. S. Elsaied, Effect of underground floor $(s)$ on seismic ..........

To accomplish the investigation of the effect of underground floor(s), 3Dfive buildings were conducted as follows:

A-Building type $\underline{\boldsymbol{A}}$ which is fixed at the ground level as shown in Fig.2

B- Building type $\underline{\boldsymbol{B}}$ which has one underground floor with fixed base as shown in Fig.3

C- Building type $\underline{C}$ which has one underground floor supported on raft as shown in Fig.3

D- Building type $\underline{\boldsymbol{D}}$ which has three underground floors with fixed base as shown in Fig.4

E- Building type $\underline{\underline{E}}$ which has three underground floors supported on raft as shown in Fig.4

For each building different number of the superstructure floors was studied namely: 2, $5,10,15$ and 20 floors.

Table 1.

Columns-raft schedule

\begin{tabular}{|c|c|c|c|c|c|c|}
\hline \multicolumn{6}{|c|}{ COLUMNS SCHEDULE (mm) } & \multirow[b]{2}{*}{$\begin{array}{l}\text { RAFT } \\
(\mathrm{mm})\end{array}$} \\
\hline $\begin{array}{c}\text { \# OF } \\
\text { STORIES }\end{array}$ & LOCATION & $\begin{array}{c}\text { FROM } \\
\text { FOUND. } \\
\text { UP TO } 5 \\
\text { STORIES }\end{array}$ & $\begin{array}{c}\text { FROM } 5 \\
\text { TO } 10 \\
\text { STORIES }\end{array}$ & $\begin{array}{l}\text { FROM } 10 \\
\text { TO } 15 \\
\text { STORIES }\end{array}$ & $\begin{array}{c}\text { FROM } \\
15 \\
\text { TO } 20 \\
\text { STORIES }\end{array}$ & \\
\hline \multirow{3}{*}{20} & CORNER & $800 \times 800$ & $700 \times 700$ & $600 \times 600$ & $500 \times 500$ & \multirow{3}{*}{2500} \\
\hline & EDGE & $1000 \times 1000$ & $900 \times 900$ & $800 \times 800$ & $700 \times 700$ & \\
\hline & INTERIOR & $1500 \times 1500$ & $1300 \times 1300$ & $1100 X 1100$ & $900 \times 900$ & \\
\hline \multirow{3}{*}{15} & CORNER & $700 \times 700$ & $600 \times 600$ & $500 \times 500$ & --------- & \multirow{3}{*}{2000} \\
\hline & EDGE & $900 \times 900$ & $800 \times 800$ & $700 \times 700$ & ---------- & \\
\hline & INTERIOR & $1300 \times 1300$ & $1100 \times 1100$ & $900 \times 900$ & ---------- & \\
\hline \multirow{3}{*}{10} & CORNER & $600 \times 600$ & $500 \times 500$ & ---------- & ---------- & \multirow{3}{*}{1500} \\
\hline & EDGE & $800 \times 800$ & $700 \times 700$ & ---------- & ---------- & \\
\hline & INTERIOR & $1100 \times 1100$ & $900 \times 900$ & ----------- & ---------- & \\
\hline \multirow{3}{*}{5} & CORNER & $500 \times 500$ & ---------- & ---------- & --------- & \multirow{3}{*}{1000} \\
\hline & EDGE & $700 \times 700$ & ---------- & ---------- & ---------- & \\
\hline & INTERIOR & $900 \times 900$ & ---------- & ----------- & ---------- & \\
\hline \multirow{3}{*}{2} & CORNER & $400 \times 400$ & ---------- & ---------- & ---------- & \multirow{3}{*}{600} \\
\hline & EDGE & $600 \times 600$ & ----------- & ----------- & ----------- & \\
\hline & INTERIOR & $700 \times 700$ & ---------- & ---------- & ---------- & \\
\hline
\end{tabular}

\section{Modeling and analysis}

In recent years, the use of the finite element method in the analysis of reinforced concrete structures, become quite often. Three dimensional finite element analyses can be considered as a powerful tool for prediction of the behavior of reinforced concrete building subjected to response spectrum earth quake lateral load. In this chapter, a general description of the finite element program used in the analysis and material are presented. Also describes the example structures used for parametric study.

\subsection{Employed finite element program}

Finite element program namely "ANSYS version 11+ Civil FEM" is employed for modeling the 3 -D buildings. 


\subsection{Material}

Fc_4000 Material properties defined by “ANSYS version 11+ Civil FEM" are standard properties. The selected material has filled out with the same parameters as the ACI-318 code requires. Some specific concrete material properties supported by CivilFEM are described hereafter:

$\begin{array}{lll}\text { Ex } & \text { Modulus of elasticity for linear analysis } & =1.6 \mathrm{E}+10 \mathrm{~kg} / \mathrm{m} 2 \\ \text { NUXY } & \text { Poisson's ratios } & =0.2 \\ \text { DENS } & \text { Mass density } & =2500 \mathrm{~kg} / \mathrm{m}^{3}\end{array}$

The effect of cracking of concrete was taking into consideration by reduce the modulus of elasticity of concrete to one-half the value of un-cracked concrete according EUROCODE clause 4.3.1 [1]

\subsection{Different used element}

\subsubsection{Concrete shell element}

SHELL63 was used to model the concrete shell elements (slabs, walls and raft) it has both bending and membrane capabilities. Both in-plane and normal loads are permitted. The element has six degrees of freedom at each node: translations in the nodal $\mathrm{x}, \mathrm{y}$, and $\mathrm{z}$ directions and rotations about the nodal $\mathrm{x}, \mathrm{y}$, and z-axes.

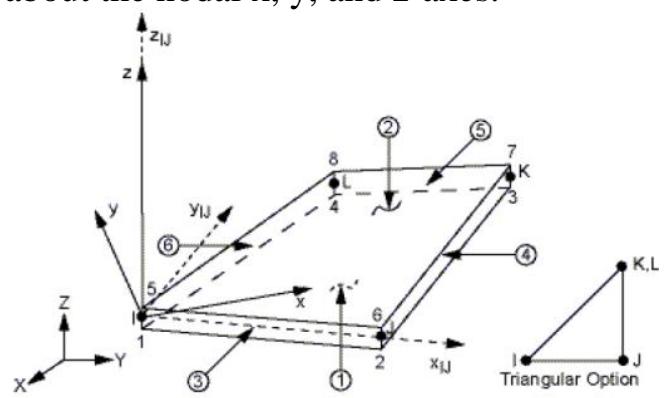

Fig. 5. Shell 63 elements for modeling of concrete shells

\subsubsection{Concrete column element}

BEAM4 was used to model the concrete column element. It is a uniaxial element with tension, compression, torsion, and bending capabilities. The element has six degrees of freedom at each node: translations in the nodal $\mathrm{x}, \mathrm{y}$, and $\mathrm{z}$ directions and rotations about the nodal $\mathrm{x}, \mathrm{y}$, and $\mathrm{z}$ axes.

\subsubsection{Spring support element}

Spring-Damper COMBIN14 was used to model the spring support element. It has longitudinal or torsional capability in 3-D application. The longitudinal spring-damper option is a uniaxial tension-compression element with up to three degrees of freedom at each node: translations in the nodal $\mathrm{x}, \mathrm{y}$, and $\mathrm{z}$ directions. No bending or torsion is considered. 


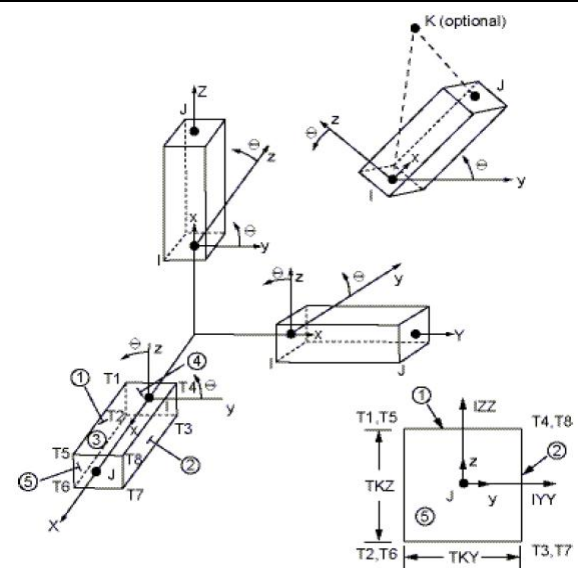

Fig. 6. Beam-4 elements for modeling of concrete columns

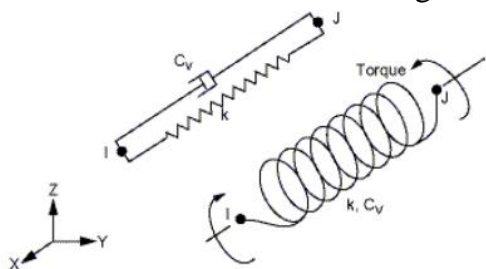

Fig. 7. COMBIN14 elements used to model the spring supports

\subsection{Boundary conditions}

The boundary conditions are chosen as fixed support or considered as spring support as per building condition under discussion.

\subsection{Spectrum calculation according to Euro code No. 8}

A single-point response spectrum was used to produce the response spectrum analysis through the following steps ([1], Euro-code 8, Design of structures for earthquake resistance, BS-EN1998-1; 2004.).

3.5.1. Design spectrum for elastic analysis

For the horizontal components of the seismic action the design spectrum, $S_{d}(T)$, were defined by the following expressions:

$$
\begin{array}{ll}
\mathrm{S}_{\mathrm{d}}(\mathrm{T})=\mathrm{a}_{\mathrm{g}} * \mathrm{~S} *\left[\frac{2}{3}+\frac{\mathrm{T}}{\mathrm{T}_{\mathrm{B}}}\left(\frac{2.5}{\mathrm{q}}-\frac{2}{3}\right)\right] & 0<\mathrm{T} \leq \mathrm{T}_{\mathrm{B}} \\
\mathrm{S}_{\mathrm{d}}(\mathrm{T})=\mathrm{a}_{\mathrm{g}} * \mathrm{~S} * \frac{2.5}{\mathrm{q}} & \mathrm{T}_{\mathrm{B}}<\mathrm{T} \leq \mathrm{T}_{\mathrm{C}} \\
\mathrm{S}_{\mathrm{d}}(\mathrm{T})=\mathrm{a}_{\mathrm{g}} * \mathrm{~S} * \frac{2.5}{\mathrm{q}} *\left[\frac{\mathrm{T}_{\mathrm{C}}}{\mathrm{T}}\right] & \mathrm{T}_{\mathrm{C}}<\mathrm{T} \leq \mathrm{T}_{\mathrm{D}} \geq \beta * \mathrm{a}_{\mathrm{g}} \\
\mathrm{S}_{\mathrm{d}}(\mathrm{T})=\mathrm{a}_{\mathrm{g}} * \mathrm{~S} * \frac{2.5}{\mathrm{q}} *\left[\frac{\mathrm{T}_{\mathrm{C}} \mathrm{T}_{\mathrm{D}}}{\mathrm{T}^{2}}\right] & \mathrm{T}_{\mathrm{D}}<\mathrm{T} \leq \mathrm{T}_{\mathrm{E}} \geq \beta * \mathrm{a}_{\mathrm{g}}
\end{array}
$$




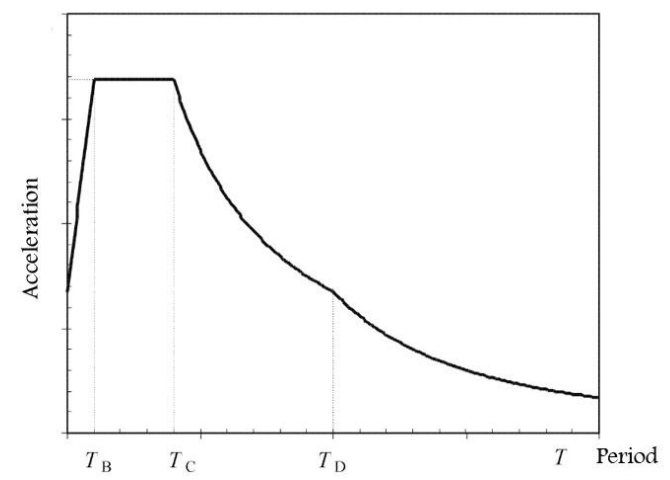

Fig. 8. Euro code design response Spectrum

Where

$\mathrm{S}_{\mathrm{d}}(\mathrm{T}) \quad$ Is the design spectrum.

$\mathrm{T}$ Is the vibration period of a linear single-degree-of-freedom system.

ag Is the design ground acceleration.

$\mathrm{S} \quad$ Is the soil factor.

$=1.00 \mathrm{~m} / \mathrm{s}^{2}$

$=1$

$\mathrm{T}_{\mathrm{B}} \quad$ Is the lower limit of the period of the constant spectral acceleration branch. $=0.15 \mathrm{Sec}$

$\mathrm{T}_{\mathrm{C}} \quad$ Is the upper limit of the period of the constant spectral acceleration branch; $=0.40 \mathrm{Sec}$

$\mathrm{T}_{\mathrm{D}} \quad$ Is the value defining the beginning of the constant displacement response $=2.00 \mathrm{Sec}$ range of the spectrum;

$\mathrm{q} \quad$ Is the behavior factor frame system(E.C.8 clause 5.2.2.2)[2] $\quad=3.45$

$\beta \quad$ Is the lower bound factor for the horizontal design spectrum. $\quad=0.2$

Damping Ratio of viscous damping ratio of the structure $[\xi]$ (in $\%$ ). $=5 \%$

Then the period-spectrum values can be drawn as follows:

Table 2

Period-spectrum values

\begin{tabular}{|c|c|}
\hline Period & $\begin{array}{c}\text { SPECTRUM } \\
\text { VALUES }\end{array}$ \\
\hline$(\mathrm{Sec})$ & $\left(\mathrm{m} / \mathrm{s}^{2}\right)$ \\
\hline 0.001 & 0.66705 \\
\hline 0.01 & 0.67053 \\
\hline 0.05 & 0.68599 \\
\hline 0.1 & 0.70531 \\
\hline 0.15 & 0.72464 \\
\hline 0.2 & 0.72464 \\
\hline 0.4 & 0.72464 \\
\hline 0.5 & 0.57971 \\
\hline 0.6 & 0.48309 \\
\hline 0.7 & 0.41408 \\
\hline
\end{tabular}

\begin{tabular}{|c|c|}
\hline Period & $\begin{array}{c}\text { SPECTRUM } \\
\text { VALUES }\end{array}$ \\
\hline$(\mathrm{Sec})$ & $\left(\mathrm{m} / \mathrm{s}^{2}\right)$ \\
\hline 0.8 & 0.36232 \\
\hline 0.9 & 0.32206 \\
\hline 1 & 0.28986 \\
\hline 1.1 & 0.26351 \\
\hline 1.2 & 0.24155 \\
\hline 1.3 & 0.22297 \\
\hline 1.4 & 0.20704 \\
\hline 1.5 & 0.2 \\
\hline 4 & 0.2 \\
\hline 5 & 0.2 \\
\hline
\end{tabular}


Magdy. M. M. Genidi and Tamer M. S. Elsaied, Effect of underground floor(s) on seismic .........

The results of the analysis are presented and discussed in the sequel.

\section{Results}

The comparison of the results between building type $\underline{\boldsymbol{A}}$ and other buildings types $\underline{B}$ to $\underline{E}$ will focus on the following variables: the natural period of vibration, the story shear, the lateral displacement and the straining actions of columns $\mathrm{A} / 3, \mathrm{~A} / 4, \mathrm{~B} / 3$ and $\mathrm{B} / 4$. These columns cover the following cases:

A-Case of column connected to concrete retaining wall along its longitudinal direction. It is represented by column $\mathrm{A} / 3$.

B- Case of column connected to concrete retaining wall at its corner .It is represented by column A/4.

$\mathrm{C}$ - Case of column not connected to concrete retaining wall but the column cross section is extended to the base of building. It is represented by column $\mathrm{B} / 3$.

D- Case of column connected to concrete wall along its transverse direction. It is represented by column $\mathrm{B} / 4$.

For these columns a specific section is studied as shown in figure 5. For building type $\underline{\boldsymbol{A}}$ it is the section at base. For buildings types $\underline{\boldsymbol{B}}$ to $\underline{\boldsymbol{E}}$ it is the section at top of underground floor(s) slab.

The comparison of the different variables is presented in form of ratios. By ratios we mean the value of a given variable for building type $\boldsymbol{B}$ to $\boldsymbol{E}$ divided by the value of the same variable for building type $\underline{\boldsymbol{A}}$.

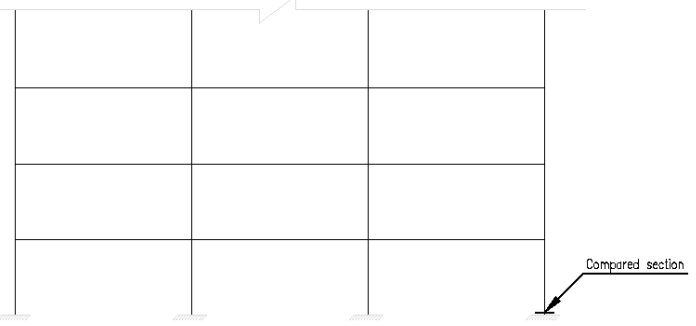

Building type A

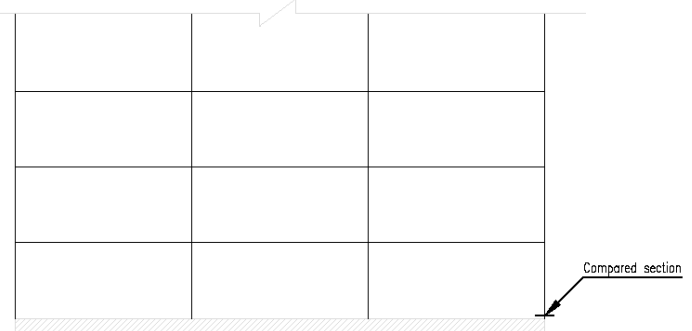

Building types B to $\mathrm{E}$

Fig. 9. Studied sections 


\subsection{Natural period of vibration, lateral displacement and story shear}

Figures 10, 11 and 12 show the increases of the natural period of vibration, the lateral displacement and the story shear ratios in buildings types $\underline{\boldsymbol{B}}$ to $\underline{\boldsymbol{E}}$. This is due to the flexibility increase of buildings provided with underground floor.

Natural period of vibration depends on the mass and the stiffness of the building. The less stiffness increases the natural period of vibration [7]. By the fact that the superstructure stiffness of buildings types $\underline{\boldsymbol{B}}$ to $\underline{\boldsymbol{E}}$ are smaller than this of building type $\underline{\boldsymbol{A}}$ (see clause 4-3 in this paper). This meets the results shown in figure 10 where the natural period of vibration ratios increase for buildings types $\underline{\boldsymbol{B}}$ to $\underline{\boldsymbol{E}}$.

The relationship between the top lateral displacement and the natural period of vibration is a positive correlation [7]. This agrees with the results shown in figure 11 where the top lateral displacement ratios increase for buildings types $\underline{\boldsymbol{B}}$ to $\underline{\boldsymbol{E}}$.

The relationship between the story shear force $(\mathrm{F})$ and the participated part of mass $(\mathrm{M})$ and the ground acceleration $(\mathrm{Sa})$ is $\mathrm{F}=\mathrm{M}^{*} \mathrm{~S}_{\mathrm{a}}[6]$. The increase of the natural period of vibration as it is represented in figure 10 decreases the ground acceleration $S_{a}$ [1].Figure 12 indicates that the story shear force ratios $\mathrm{F}$ are increased. Hence, the participated part of mass $\mathrm{M}$ is increased. Therefore it can be concluded that the participated part of the superstructure mass on buildings types $\underline{\boldsymbol{B}}$ to $\underline{\boldsymbol{E}}$ is greater than that on building type $\underline{\boldsymbol{A}}$ of such buildings.

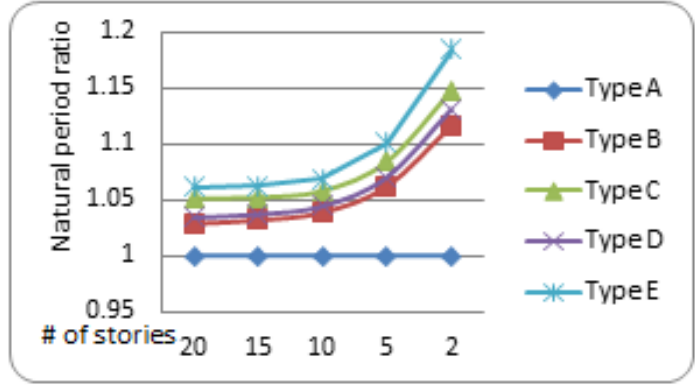

Fig. 10. Comparison between natural period ratios of vibration ratios

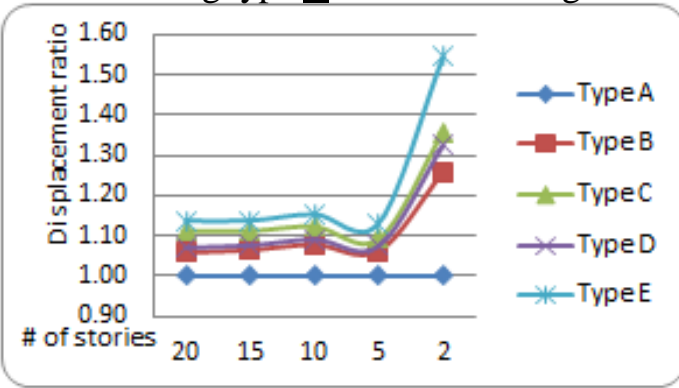

Fig. 11. Comparison between lateral displacement

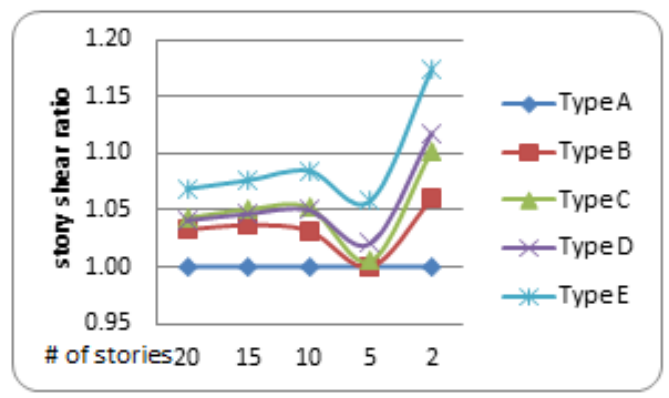

Fig. 12. Comparison between story shear ratios 
Magdy. M. M. Genidi and Tamer M. S. Elsaied, Effect of underground floor(s) on seismic .........

\subsection{Bending moment and shear force ratios of columns}

Comparison of the moment and the shear ratios for columns A/3, A/4, B3 and B/4 were performed in the sequel.

\subsubsection{Column at axes $A / 3$}

Figures 13 and 14 show that the bending moment and the shear force ratios increased for buildings types $\boldsymbol{B}$ to $\boldsymbol{E}$. This is due to the greater stiffness of columns connected to the retaining wall.

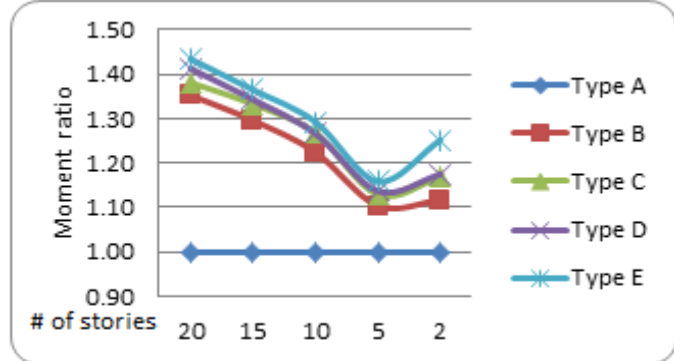

Fig. 13. Moment ratio at column axes $A / 3$

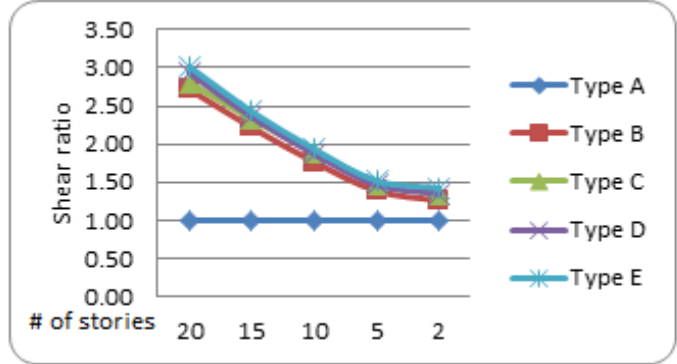

Fig. 14. Shear ratio at column axes $A / 3$

\subsubsection{Column at axes $A / 4$}

Figures 15 and 16 show that the bending moment and the shear force ratios increased for buildings types $\boldsymbol{B}$ to $\boldsymbol{E}$. This is due to the greater stiffness of columns connected to the retaining wall.

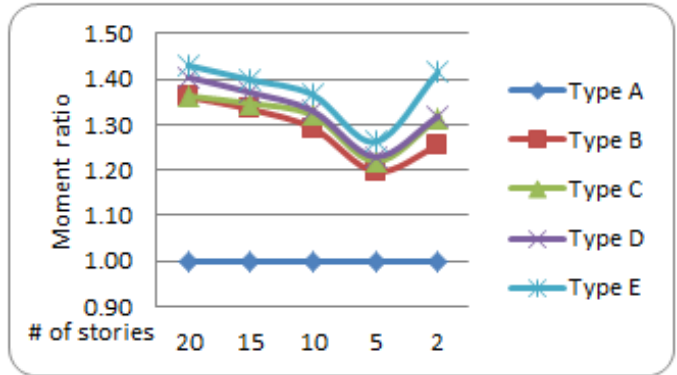

Fig. 15. Moment ratio at column axes $\mathrm{A} / 4$

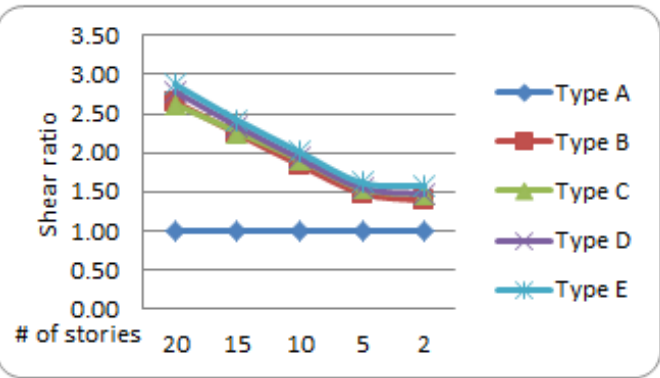

Fig. 16. Shear ratio at column axes $\mathrm{A} / 4$

\subsubsection{Column at axes $B / 3$}

Figures 17 and 18 show that the bending moment and the shear force ratios decreased for buildings types $\underline{\boldsymbol{B}}$ to $\underline{\boldsymbol{E}}$. This is due to the redistribution of lateral force between columns according to their new stiffness (Underground floor(s) wall effect).

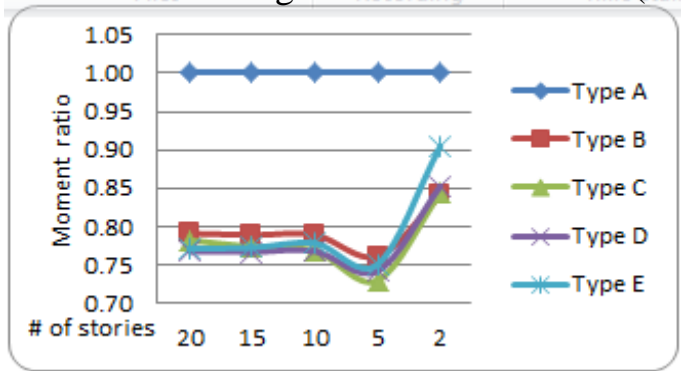

Fig. 17. Moment ratio at column axes $B / 3$

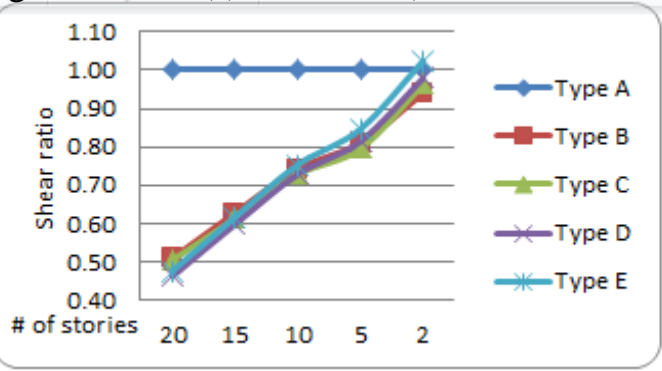

Fig. 18. Shear ratio at column axes $B / 3$ 


\subsubsection{Column at axes $B / 4$}

Figures 19 shows that the bending moment ratio decreased for buildings types $\underline{\boldsymbol{B}}$ to $\underline{\boldsymbol{E}}$.

Figure 20 shows that the shear force ratio decreased for buildings types B to Except for buildings which have 2 superstructure stories in which it is increased. This is due to their distribution of the lateral force between columns according to their new stiffness.

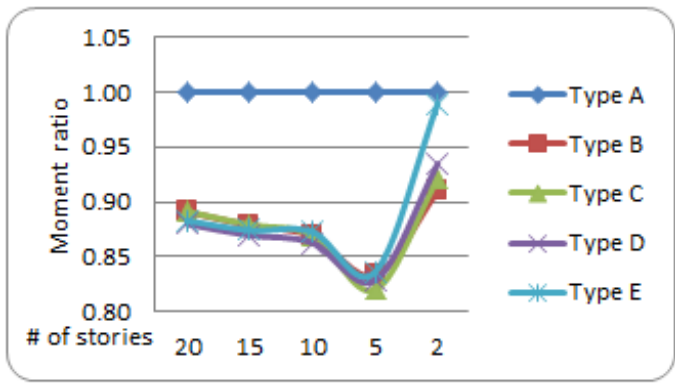

Fig. 19. Moment at column axes $B / 4$

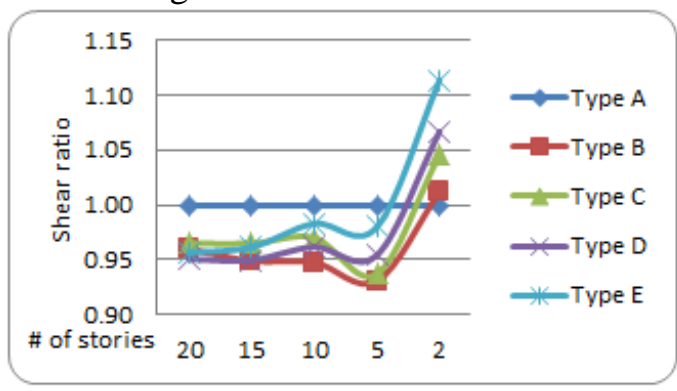

Fig. 20. Shear at column axes $B / 4$

\subsection{Discussion}

The stiffness of a column depends on its dimensions and its top and bottom connection/restraint. In building type $\underline{\boldsymbol{A}}$ due to the absence of underground floor(s) the base columns are considered fixed at their lower end. In buildings types B to E the stiffness of columns at the floor(s) above depends on their connections to the element below it. For example, in building type $\underline{\boldsymbol{A}}$ column at axis A/3 has a bottom fixed restraint while in building types $\underline{\boldsymbol{B}}$ to $\underline{\boldsymbol{E}}$ it is connected to a reinforced concrete wall in its longitudinal direction. By the fact that the R.C. retaining wall along its longitudinal direction acts as fixed restraint while along transverse direction (or the case of column cross section is extending to the underground floor) are not. Hence, the stiffness of columns at axes $\mathrm{A} / 3$ and A/4 are the same in all buildings while the stiffness of columns at axes B/3 and B/4 in building types $\underline{\boldsymbol{B}}$ to $\underline{\boldsymbol{E}}$ have stiffness less than that in building type $\underline{\boldsymbol{A}}$.

Lateral load distributed to columns depends on their stiffness. Hence, lateral load distributed to columns at axis B/3 and B/4 in building type $\underline{A}$ are greater than those distributed to the same columns in building types $\underline{\boldsymbol{B}}$ to $\underline{\boldsymbol{E}}$ due to the reduction of their stiffness.

Whereas the story shear is almost the same for all buildings ( from $\underline{\boldsymbol{A}}$ to $\underline{\boldsymbol{E}}$ ), In buildings types $\underline{\boldsymbol{B}}$ to $\underline{\boldsymbol{E}}$. while the lateral load distributed for columns $\mathrm{B} / 3$ and $\mathrm{B} / 4$ are decreased. Lateral load distributed for columns $\mathrm{A} / 3$ and $\mathrm{A} / 4$ are increased sequentially. This is shown in figures 13 to 16 where the moment and shear ratios increase in columns $\mathrm{A} / 3$ and $\mathrm{A} / 4$ and in figures 17 to 20 . However, the moment and shear ratios decrease in columns at $\mathrm{B} / 3$ and $\mathrm{B} / 4$.

\subsection{Simplified model}

Simplified four 2D frames are used to simplify the frames along axes (A) \& (B) of buildings types $\underline{\boldsymbol{A}}$ and $\underline{\boldsymbol{B}}$ which have five superstructure stories. While the top lateral displacement of the frames indicates the stiffness, the top lateral displacement of the Frames of building type $\underline{\boldsymbol{A}}$ will compared to those of building type $\underline{\boldsymbol{B}}$. Figures 21 to 24 shows the simplified SAP model, elements dimension (in meter) and the applied lateral loads (triangle 
Magdy. M. M. Genidi and Tamer M. S. Elsaied, Effect of underground floor(s) on seismic ..........

load from 0.00 at the top of underground floor(s) slab to 10.00 ton at $5^{\text {th }}$ story). Frame \#1 simulates the frame along axis (A) of building type $\underline{\boldsymbol{A}}$, Frame \#2 simulates the frame along axis (A)of building type $\underline{\boldsymbol{B}}$, Frame \#3 simulates the frame along axis (B)of building type $\underline{\boldsymbol{A}}$ and Frame \#4 simulates the frame along axis (B)of building type $\underline{\boldsymbol{B}}$.

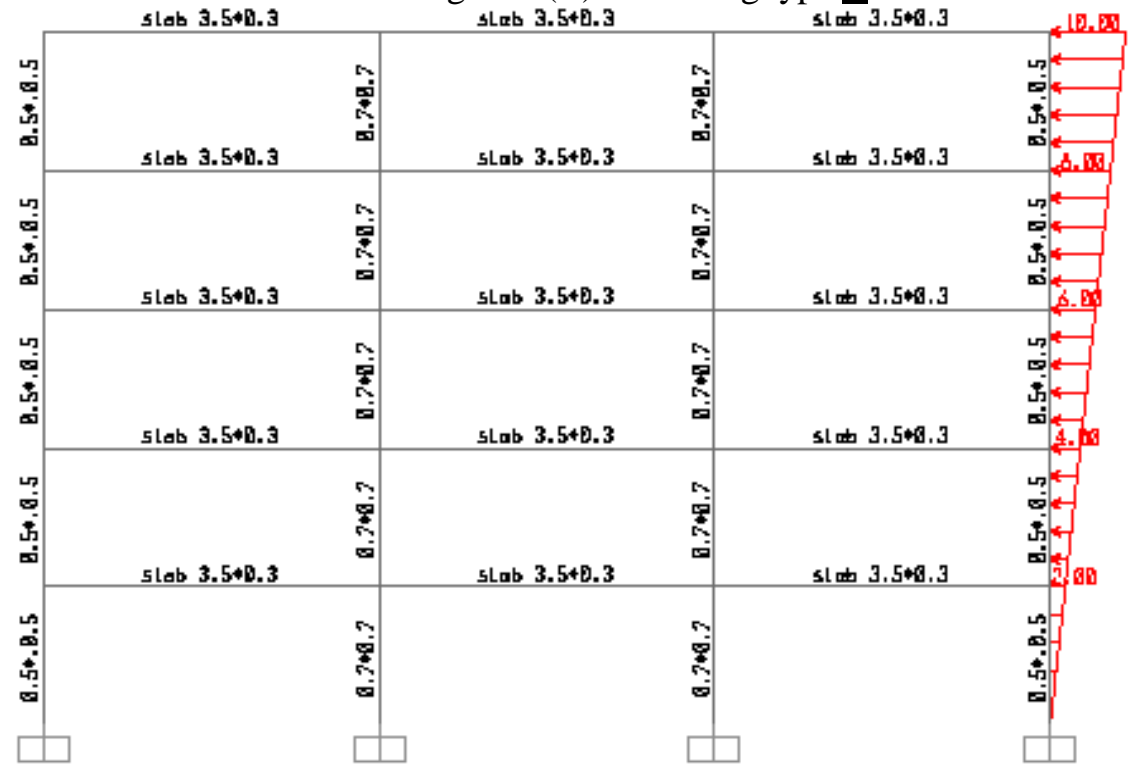

Fig. 21. Frame $\# 1$ at axis (A), building type $\underline{A}$

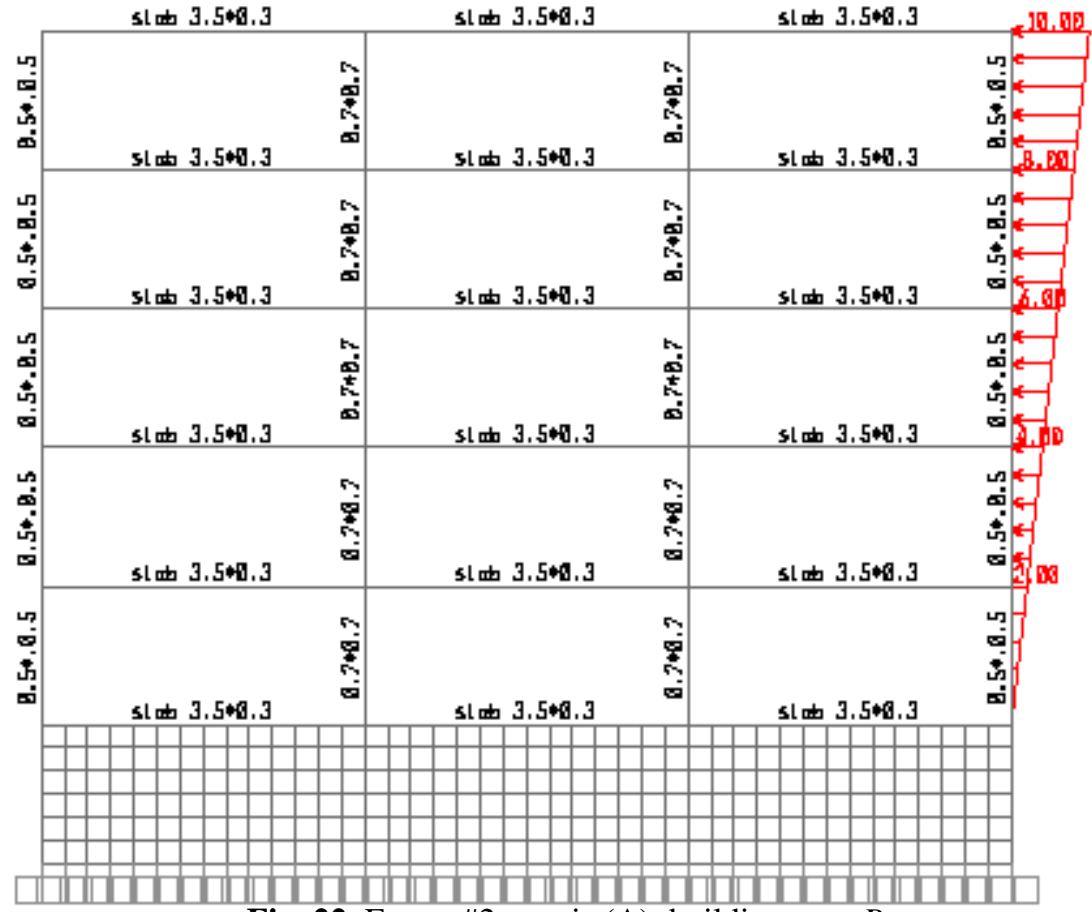

Fig. 22. Frame $\# 2$ at axis (A), building type $\underline{B}$ 


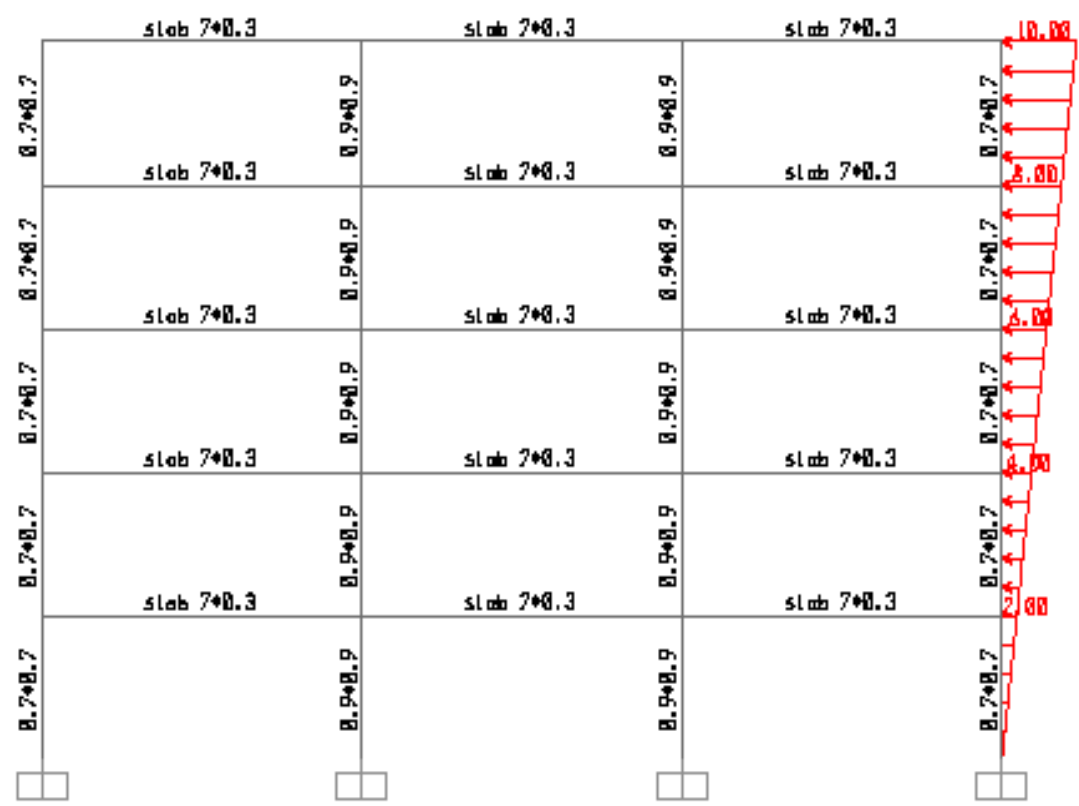

Fig. 23. Frame $\# 3$ at axis (B), building type $\underline{A}$

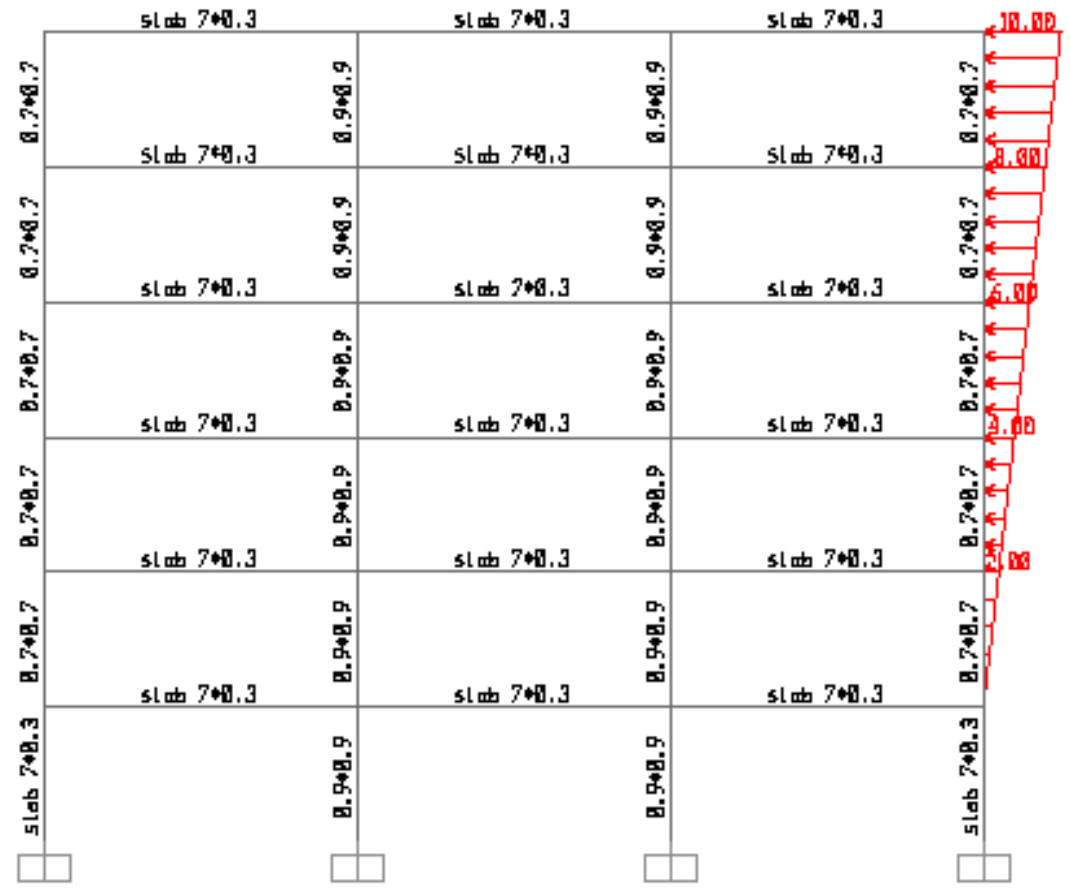

Fig. 24. Frame $\# 4$ at axis (B), building type $\underline{B}$ 
Magdy. M. M. Genidi and Tamer M. S. Elsaied, Effect of underground floor(s) on seismic .........

Figures 25 to 28 shows the resulting top lateral displacements.

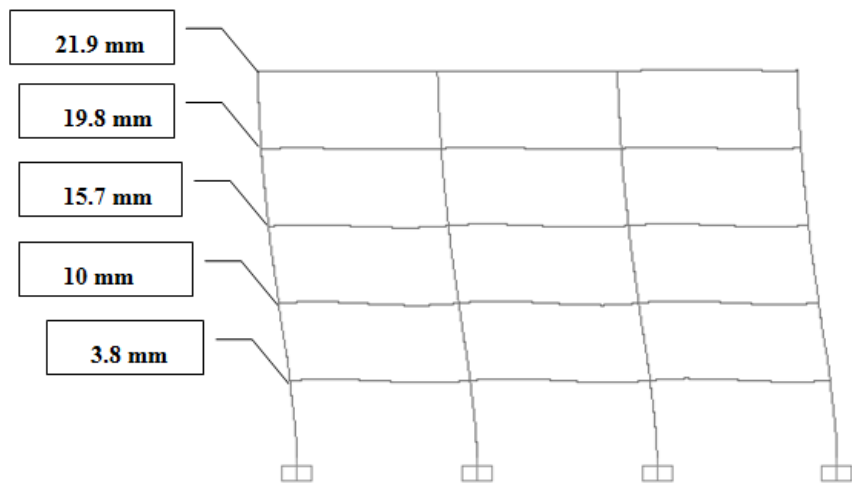

Fig. 25. Top lateral displacement of Frame \#1

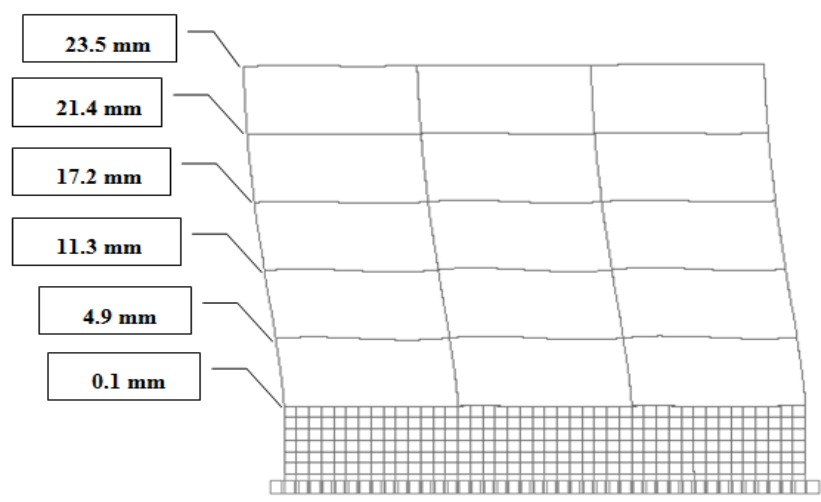

Fig. 26. Top lateral displacement of Frame \#2

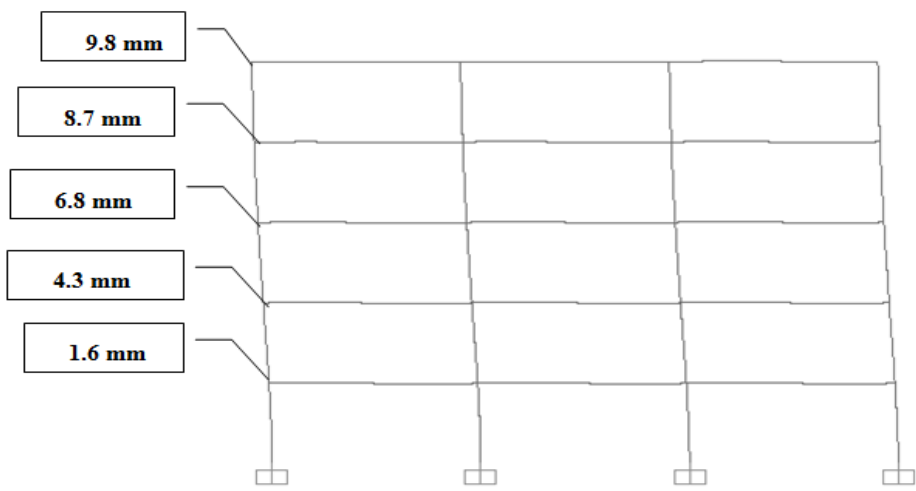

Fig. 27. Top lateral displacement of Frame \#3

Figures 25 and 26 show that the stiffness of the frame along axis (A) decreased for building type $\underline{B}$ than that for building type $\underline{A}$ with ratio of the displacement $22 / 33=0.96 \%$. While figures 23 and 24 show that the stiffness of the frame along axis (B) decreased for building type $B$ than that of building type $\underline{A}$ with the ratio of the displacement $10 / 14=$ $0.71 \%$. Hence, the stiffness of the frame along axis (B) decreased more than that in the 
frame along axis (A).In building type $\underline{B}$, the lateral load distributed for frame along axis (B) decreased than that of building type $\underline{A}$, and this decreases will lead to increase the lateral load distributed for frame along axis (A).

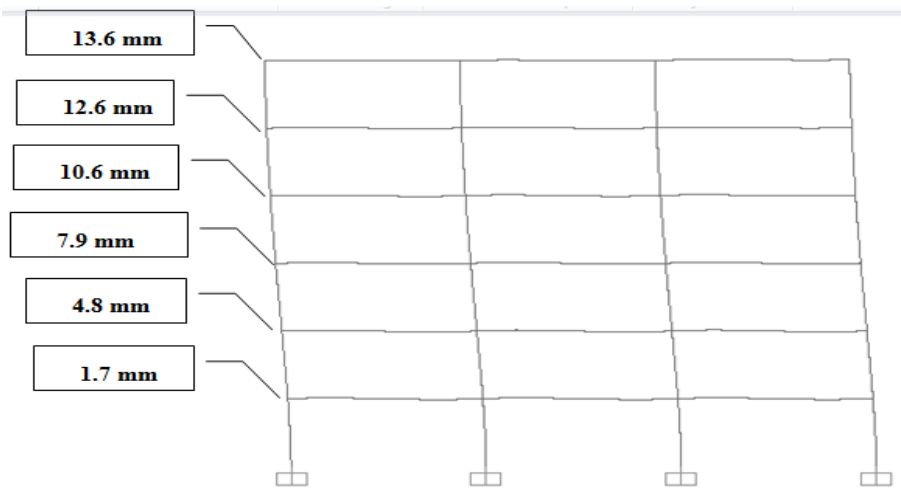

Fig. 28. Top lateral displacement of Frame \#4

The results of the simplified SAP model agreed with the results of the straining action, where as figures 17 to 20 show the decreases of the moment and the shear ratios in columns $\mathrm{B} / 3$ and $\mathrm{B} / 4$ (frame \#2) and figures 13 to 16 show the increases of the moment and the shear ratios in columns $\mathrm{A} / 3$ and $\mathrm{A} / 4$ (frame\#1).

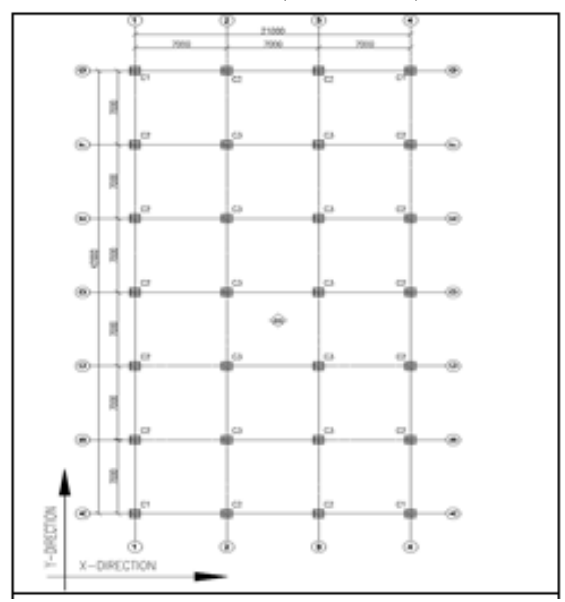

Fig. 29. Typical plan

\section{Additional examples investigated}

\subsection{Alternative building plan}

Example structure which is the same as example structure stated in clause 4.1 except the plan of repetitive story slab. This example has a rectangular plan as shown in Fig.29. This example structure was developed to investigate the effect of the building rectangularity.

A response spectrum seismic load in $\mathrm{X}$-and $\mathrm{Y}$-directions were assigned to every building to investigate the internal straining actions in columns at axes $\mathrm{A} / 3, \mathrm{~A} / 4, \mathrm{~B} / 3, \mathrm{~B} / 4, \mathrm{D} / 3$ and D/4. 
Magdy. M. M. Genidi and Tamer M. S. Elsaied, Effect of underground floor (s) on seismic .........

The results of this example have the same behavior as the results of Example structure stated in clause 4.1 .

\subsection{Alternative Winkler support stiffness}

This example structure which is similar to that stated in clause 5-1was developed to investigate the effect of variation of Winkler spring support stiffness.

The vertical spring support stiffness for building types $\underline{C}$ and $\underline{E}$ was changed from $0.4 \mathrm{~N} / \mathrm{mm}^{3}$ (provide around $1 \mathrm{~mm}$ settlement) to $0.007 \mathrm{~N} / \mathrm{mm}^{3}$ (provide around $20 \mathrm{~mm}$ settlement).

The results of this example exhibit the same behavior as those of Example structure stated in clause 4.1 .

\section{Conclusions}

The effect of the underground floor(s) on the seismic response of buildings was investigated in this study and the following conclusions could be drawn.

1- The natural period of vibration of building structure may be significantly underestimated if the underground floor(s) of the building is ignored in the analysis.

2- The lateral displacements of building structure may be significantly underestimated if the underground floor(s) of the building is ignored in the analysis.

3- The story shear of building structure may be significantly underestimated if the underground floor(s) of the building is ignored in the analysis.

4- Lateral forces distribution for buildings considering underground floor(s) is significantly different from that for buildings ignoring underground floor(s) and considering the superstructure fixed to the underground floor(s) top slab.

5- For buildings with basement, considering the superstructure fixed at the underground floor(s) top slab will affect the internal straining actions in peripheral columns at the top of underground floor(s) slab. These can reach one third of the values of the case where the superstructure and underground floor(s) are considered. Therefore, it is necessary to include the effect of underground floor(s) in the analysis of the considered (or similar) building structures.

6- For buildings with basement, considering the superstructure fixed at the underground floor(s) top slab will affect the internal straining actions in internal columns at the top of underground floor(s) slab. These can reach 1.2 of the values of the case where the superstructure and underground floor(s) are considered. Therefore, it is necessary to include the effect of underground floor(s) in the analysis of the considered (or similar) building structures.

\section{REFERENCES}

[1] Euro-code 8, Design of structures for earthquake resistance, BS-EN1998-1; 2004.

[2] Egyptain code of Practice to calculate loads and forces in construction and bulidings works No 201,2012 . 
[3] Lee D.-G. \& Kim H.S., "Efficient seismic analysis of high-rise buildings considering the basements", NZSEE 2001 Conference.

[4] Soydemir C. \& Celebi M., "seismic design of buildings with multi-level basements", Earthquake Engineering, Tenth World Conference $\odot$ 1992Balkema, Rotterdam, isbn 90 542100605 .

[5] Junsheng C.C.F.Z, " Dynamic calculation model of the high-level structure with a basement", Jornal of South China University of Technology (Natural Science Edition) Vol.33 No. 6 June 2005.

[6] Chopra A.K., " Earthquake Dynamics of Structures: A Primer, Second Edition", Earthquake Engineering Research Institute, Oakland, Calif.,2005.

[7] Mario P., "Structural-Dynmics, theory and computation", Van Nostrand Reinhold Company Inc. 1985. 


\section{تأثير البدروم في التحليل الزلزالى للمبانى}

\section{الملخص العربى}

بعض المبانى قد تحتوى على بدرومات تستخدم كمو اقف للسيار ات أو مر اكز للتسوق وما إلى ذلك. الحالـة

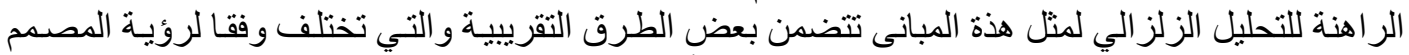

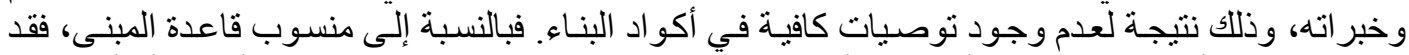

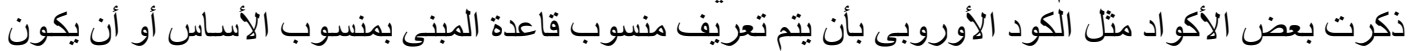

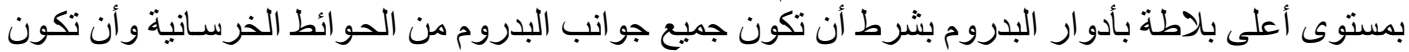

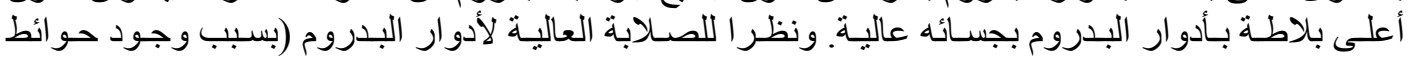

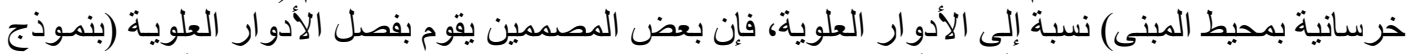

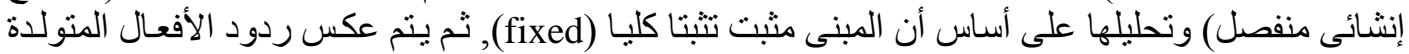

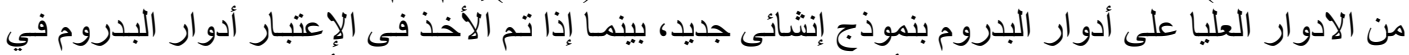

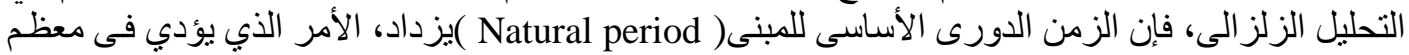

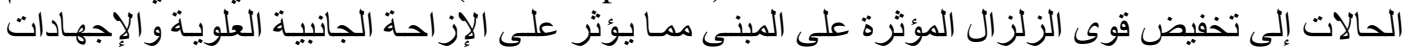

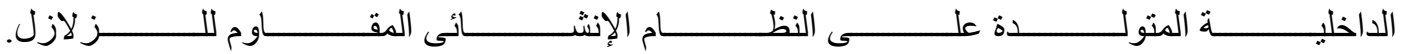

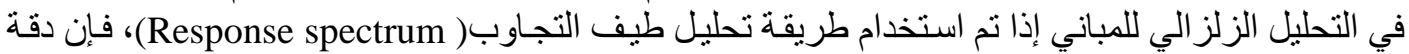

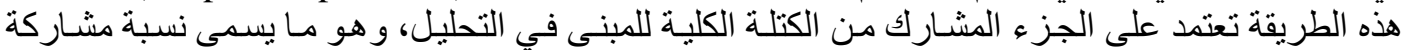
الكتلة (Mass participation ratio)

الهدف الرئيسي من هذه الدراسة هو فهم أفضل للمقاومة الزلز الية للمبانى التى تشتمل أدوار بدروم. بنساء

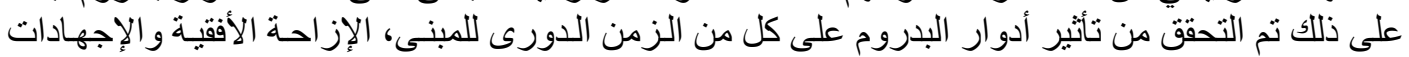

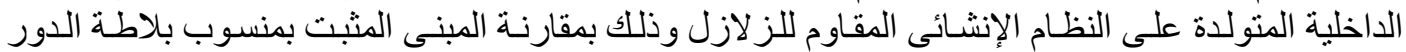

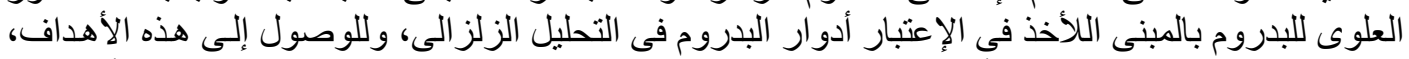

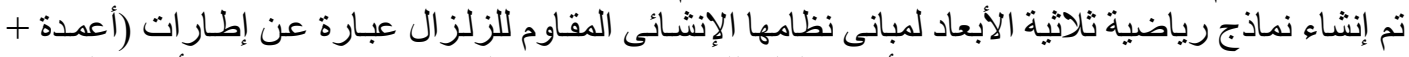

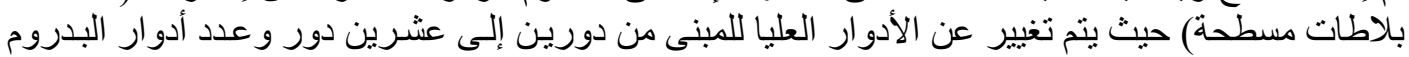

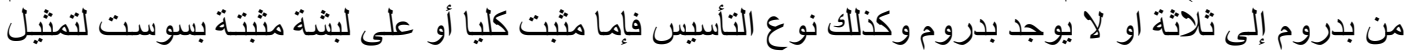

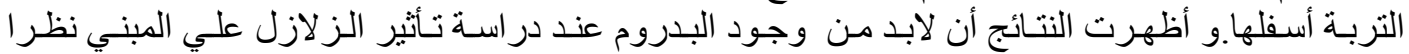

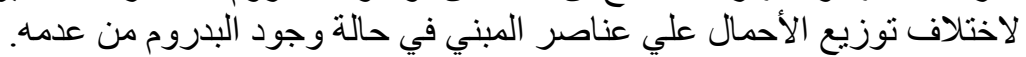

